\title{
APPLYING OF ACTIVITIES MANAGEMENT BASED ON SELF-LEARNING
}

\author{
Valerii Samsonkin \\ Golda Meir Ukrainian-Israel Institute of Strategic Researches \\ 6 Olginskaya str., Kyiv, Ukraine, 01001 \\ samsonkin1520mm@gmail.com \\ Valerii Druz' \\ Department of Biomechanics \\ Kharkiv State Academy of Physical Culture \\ 99 Klochkivska str., Kharkiv, Ukraine, 611058 \\ valeriidruz@gmail.com \\ Albert Feldman \\ Golda Meir Ukrainian-Israel Institute of Strategic Researches \\ 6 Olginskaya str., Kyiv, Ukraine, 01001 \\ albert@ogs.in.ua
}

\begin{abstract}
The article is devoted to a brief presentation and application in practice of an effective management way of human activities and human-technical communities one. This way was called Method of statistical regularity (Method of self-organizing processes). In fact, this is a system approach. For the first time, the application of this approach is shown on the example of quality management of the technological process. Practical management is shown using an algorithm. The effectiveness of the author's system approach is explained by the consideration of the final result of the activity as a goal and a system-forming factor of activity, taking into account the individual features of the management object, real statistics of activity. The system approach described in the article is a universal devise of management. It can be used and already used to manage individual functions of the enterprise, the process, the human operator, the community.
\end{abstract}

Keywords: system approach, norm, statistics, variation, management, self-organizing, standard deviation, system-forming factor, effectiveness, activity

\section{Introduction}

The creation [1] - a follower and associate of Vygotsky - general psychological theory of activity (AT) is largely associated with Kharkov. This approach stimulated the emergence and development of new directions in psychology, occupational hygiene, ergonomics, engineering psychology [2].

For a long time this theory was used in the study of activity. However, with the development of mechanization and automation in the industry, in transport [3], and in the military sphere, it became obvious that direct application of the theory of activity is impossible. Therefore, in the 1970 $\mathrm{s}$, a more advanced theory of applied activity (AAT) was created in the works $[4,5]$. At the same time, the theoretical foundations of Vygotsky-Leont'ev-Rubinshtein became the philosophical basis of the AAT [4]

The effectiveness of AAT was confirmed in ergonomic techniques. The most representative objects of introduction were aircraft systems, automated control systems for technological processes, remote control, software.

The further development of AAT led to the creation of the theory of systematic-structural activity (SSAT), as an independent direction in AAT.

The basic principles of SSAT are very much in tune with the scientific direction of Valerii Samsonkin and Valerii Druz', named the Method of Statistical Regularity or the Method of Self-Organizing Processes (MSOP) in the management of processes and objects. 
MSOP is the answer to the modern challenge, which is characterized by global informatization, the massive use of robots, automation of transport and production processes, the concept of automation "Industry 4.0".

The essence of SMEs is a system approach to managing the production process. This method is based on the statistical regularity in obtaining an equifinal end result of the "human-object management-environment" systems. The theoretical basis of SMEs was the theory of the functional system of P. K. Anokhin, the theory of the norm and the functional optimum, the principles of self-organization, the paradox of development, remarkable curves in geometry, and other sources.

The most significant theoretical results in the development of this direction are:

- proof of the V. Samsonkin's theorem "Dependence between the Complexity of System Organization and the Tolerance of the Space of Its Activity" [6, 7], and the theorem of Druz'-Samsonkin "Differentiation of elements of a homogeneous nature when a certain density of their accumulation is reached," which leads to the formation of orgogenesis, which is expressed by an external mapping of the intrinsic properties of the original elements [6];

- development by J. Puhach method of constructing the features of semantic spaces using a single measure of the comparison of parameters. This allows to establish an orderly ranking of their significance in obtaining an equipotential final result in management [8, 9];

- researches of A. Feldman in the field of forecasted development of civilization.

The purpose of the study is presentation of the theoretical approach and practical use of effective management of activities of human, community, technological process, enterprise/organization.

\section{Materials and methods}

\section{1. Rationale of a system approach for management}

Management is the targeted influence of a subject on an object in a permanent process of analyzing, developing, adopting and implementing solutions aimed at achieving a final positive result. Process/organization management is a multi-disciplinary problem in various fields of knowledge: psychology, HR, economics, technology, computer science, mathematics and others [10].

Practically there is no detailed analysis and in-depth studies of the content and features of the technology of the organizational and managerial component of professional activity in the psycho-administrative literature. Ensuring the effectiveness of management requires from the performer a new level and character of thinking, which correspond to the level of complexity of his activities. Characteristic features of the new thinking: systematic, flexible, responsive, non-standard approach to decision making.

Until the 20th century, practically no one thought about the system management of the organization from the point of view of psychology, either from the point of view of technology or from the point of view of management [11].

The activity of TOP-management should be oriented towards a systematic understanding of all interrelated main components of the organization's activities. Management decisions are the most important tool for overcoming emerging conflicts, coordinating interests and coordinating activities. This is the choice of the best option from alternatives. This is the choice between "seeming right" and "probably wrong", but more often - the truth of the options is unprovable. An effective solution does not follow from the logical chain of agreement of facts.

Often the choice of the option is made intuitively.

The search for the optimal ratio in joint activity was conducted by Weinberg, Hardy, Lorentz (Weiss-Lapick, Hardy-Weinberg laws). The most profound are the Volterra models. The union of the laws of Zipf-Pareto, Lotka-Volterra and Gauss allows to find the boundaries of a stable correlation and commensurability of personal freedom and social dependence or discipline. This is presented in $[6,12]$. 


\section{2. The essence of the idea}

The general scheme of the proposed system approach is presented in Fig. 1. Outwardly, it does not differ from the classical formulation of the control problem. But in order to understand the features of the control process, which claims to be effective, let's briefly describe the essence of the presented blocks.

\section{- “Identification ..." block.}

This block solves two problems:

a) evaluation of the state of the managed object;

b) systematization of the results of the activity process.

a) Evaluation of the state of the managed object.

First of all, let's define the terminology. Under the state of the controlled object, in accordance with P. K. Anokhin [13], let's understand the level of activity of its elements, reflected in obtaining the final result.

An evaluation of the state of the system is made by comparing the control parameter with the norm of the system behavior. If the control parameter corresponds to this norm, it is said that the control object is in the state of a functional optimum.

A few words about the number of control parameters. It is believed that the more of them, the more accurate the assessment of the state. However, it is not.

Many studies (I. Prigozhin, G. Haken, A. Dul'din, V. Druz', V. Samsonkin) prove the possibility of considering a small number of variables, which are named order parameters. In the limit, this is one parameter. This is proved by the $\pi-$ theorem [6]. On the other hand, V. Druz' proved that the equipotential value of the final result can be achieved by various participation of the constituent parameters. Therefore it is sufficient to have statistics of one parameter. By processing these statistics properly, it is possible to determine the norm of the behavior of the entire object.

In reality, the number of control parameters is greater than one. It takes a long time for people to be convinced of the effectiveness and sufficiency of just one control parameter [7].

It should be noted that the correct choice of the control parameter is sometimes a difficult task. It is necessary to represent the process or object of management well. The control parameter must, firstly, be measured, and secondly, it must be varied within a fairly wide range.

And now about technology of an estimation of a condition. Control parameters $\overline{\mathrm{PAR}}=\left\|\mathrm{p}_{1}, \mathrm{p}_{2} \ldots, \mathrm{p}_{\mathrm{n}}\right\|$ are compared with the admissions $\overline{\mathrm{LIM}}=\left\|1_{1}, \mathrm{l}_{2}, \ldots, \mathrm{l}_{\mathrm{n}}\right\|$ that characterize the necessary but not sufficient conditions of the activity: if $p_{i}$ correspond to $l_{i}(i=\overline{1, n})$, then the process is in regular mode; otherwise, it is necessary to move quickly to bring the activity in regular mode.

Then, depending on the difference between the current and previous values of $\mathrm{p}_{\mathrm{i}}$, as well as the tolerance level

$$
\Delta=\frac{\max \left(\mathrm{p}_{\mathrm{i}}\right)-\min \left(\mathrm{p}_{\mathrm{i}}\right)}{6}
$$

the current value of the $p_{i}$ is added to one of the seven sets $M_{-3}, M_{-2}, M_{-1}, M_{0}, M_{+1}, M_{+2}, M_{+3}$. A pair $\left(\mathrm{p}_{\mathrm{i}}, \mathrm{M}_{\mathrm{j}}\right)$ characterizes the current state of the research object, which is indicated in Fig. $\mathbf{1}$ as the output ' 1 '. Let's write the foregoing in the form of a mathematical formula:

$$
\text { ' } 1 \text { ': state }=\left(\mathrm{p}_{\mathrm{i}}, \mathrm{M}_{\mathrm{j}}\right) \text {, where } \mathrm{i}=\overline{1, \mathrm{n}}, \mathrm{j}=-1,-2,-3,0,+1,+2,+3 \text {. }
$$

It should say a few words about tolerance. This is one of the main principles of this theoretical approach. Tolerance is understood in the sense of "indistinguishability, inaccuracy, fuzziness". Greater (high) tolerance is understood as a wide range of manifestation of the control parameter or low accuracy. Low tolerance is equivalent to high accuracy and discernibility.

Today human activity is the main source of tolerance in human-machine systems (HMS). It is the person inherent in untimely action, insufficient knowledge of the situation, lack of competence, inadequate control over the process being performed. In the work of technical means, there 
is also a certain range of reliable and stable functioning. Similarly, it is possible to say about the environment. In all cases, it is necessary to consider the boundaries of the change in the control object in which there is an equilibrium state and the necessary reliability of the HMS.

Fig. 1. The general idea of the control and management of activities

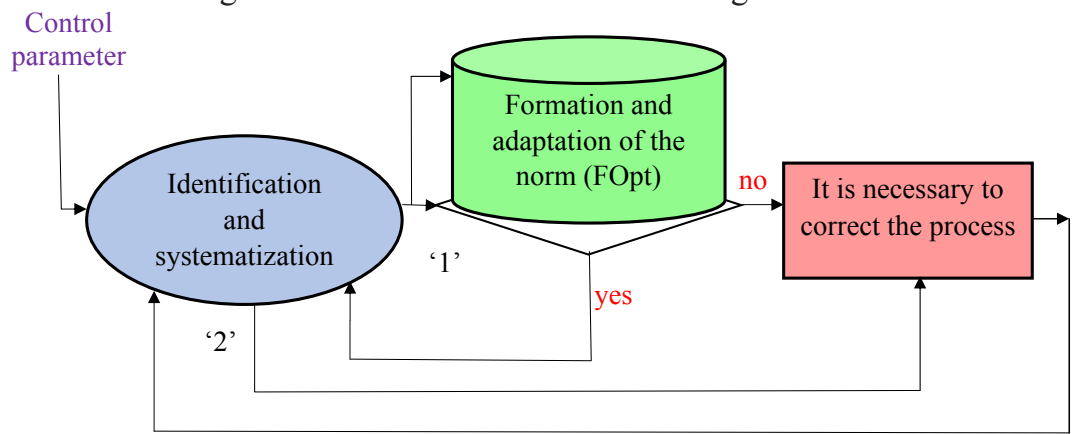

By processing the information flow, any HMS suffers a certain inaccuracy. Practically this inaccuracy should increase with the complication of information. Intuitively, the assumption is obvious: the more vague information about the analyzed process, the less certain actions of the HMS.

From the point of view of mathematics, the transition from the vague concept of "identity" to a precisely defined type of relationship is accompanied by the introduction of the term "equivalence". Similarly, the mathematical relation, corresponding to our intuitive notion of similarity or indistinguishability, was named "tolerance".

Let's call a binary relation "equivalence" on a finite-dimensional set $A=\left\{a_{1}, a_{2}, \ldots, a_{K}\right\}$. The equivalence relation is generally defined on a set $\mathrm{A} \times \mathrm{A}$ and has properties:

(i) reflexivity: $\mathrm{a}_{\mathrm{i}} \approx \mathrm{a}_{\mathrm{i}}\left(\forall \mathrm{a}_{\mathrm{i}} \in \mathrm{A}\right)$;

(ii) symmetry: $\mathrm{a}_{\mathrm{i}} \approx \mathrm{a}_{\mathrm{j}} \Rightarrow \mathrm{a}_{\mathrm{j}}=\mathrm{a}_{\mathrm{i}}\left(\forall \mathrm{a}_{\mathrm{i}}, \mathrm{a}_{\mathrm{j}} \in \mathrm{A}, \mathrm{i} \neq \mathrm{j}\right)$;

(iii) transitivity: $\mathrm{a}_{\mathrm{i}} \approx \mathrm{a}_{\mathrm{j}}, \mathrm{a}_{\mathrm{j}} \approx \mathrm{a}_{\mathrm{k}} \Rightarrow \mathrm{a}_{\mathrm{i}}=\mathrm{a}_{\mathrm{k}}\left(\forall \mathrm{a}_{\mathrm{i}}, \mathrm{a}_{\mathrm{j}}, \mathrm{a}_{\mathrm{k}} \in \mathrm{A}, \mathrm{i} \neq \mathrm{j} \neq \mathrm{k}\right)$.

"Tolerance" is a binary relation on a set $\mathrm{A} \times \mathrm{A}$, that has properties :

(i) reflexivity: $\mathrm{a}_{\mathrm{i}} \approx \mathrm{a}_{\mathrm{i}}\left(\forall \mathrm{a}_{\mathrm{i}} \in \mathrm{A}\right)$;

(ii) symmetry: $\mathrm{a}_{\mathrm{i}} \approx \mathrm{a}_{\mathrm{j}} \Rightarrow \mathrm{a}_{\mathrm{j}}=\mathrm{a}_{\mathrm{i}}\left(\forall \mathrm{a}_{\mathrm{i}}, \mathrm{a}_{\mathrm{j}} \in \mathrm{A}, \mathrm{i} \neq \mathrm{j}\right)$;

(iii) NON transitivity: $\mathrm{a}_{\mathrm{i}} \approx \mathrm{a}_{\mathrm{j}}, \mathrm{a}_{\mathrm{j}} \approx \mathrm{a}_{\mathrm{k}} \Rightarrow \mathrm{a}_{\mathrm{i}}=\mathrm{a}_{\mathrm{k}}$ at least for one triad (i, j, $\mathrm{k}$ ).

b) Systematization of the results of the activity process.

When solving the second task, such operations are performed:

(i) a database of control parameters is formed. The deeper the background of the database, the more reliable the statistical results. The more often the measurement, the more adequately controlled (monitored) the state of the control object. At least it is possible to say: it is necessary to measure the control parameter at each receipt of the final result of activity (1 time per mint, 1 time per hour, several times a day, etc.);

(ii) there is a systematization of control parameters. Systematization is a description of the control parameter in the form of answers to eight questions, which fully describe it:

WHAT measured - value of parameter;

WHERE measured - localization in the object;

WHEN - time of the measurement;

WHY - reasons for obtaining a value;

HOW - the features of the measurement;

WHO - responsible;

TO WHOM - the destination of the final result;

FOR WHAT - motivation.

Answers to questions can be obtained online; 
(iii) the dynamics of changes in the components of systematization and their mutual dependence is analyzed. This is done in the space of two or three components of systematization. For example: (WHAT-WHERE), (WHO-WHY), (WHAT-WHERE-WHEN), etc. The purpose of such analysis is finding trends/patterns that will help identify bottlenecks.

Output ' 2 ' of this block is the transfer of identified trends/patterns to find options for changing of a managed object activity.

\section{- "Formation and adaptation of the norm" block}

The term "norm" is key concept in this system approach. This term is widely used in the natural, social, technical sciences.

In engineering and natural science, the notion of the average-statistical/population norm has become most widespread.

The population norm expresses something "extremely general," "trend," or "average." Naturally, the population or "generalized" norm for a set of phenomena, objects or people cannot correspond to the norm of a real object or the individual norm of an individual.

The deepest and most reasonable interpretation is the interpretation of the norm as a functional optimum. The foundations of such understanding of the norm were laid in the early twentieth century by P. Anokhin in the theory of functional systems [14]. Later these ideas were developed in the works of K. Sudakov, A. Korol'kov, V. Petlenko, N. Amosov, Yu. Antonomov, V. Druz', Hirata, Kaku, etc. $[6,11]$.

The functional expediency of achieving the final result is the determining factor in the development of behavior, documents, forms of relations. All this makes up the norm of the system provided that the stability of interaction with the environment is maintained. In this case, the norm is:

a) as an ordered structure of relations;

b) as the process of maintaining a state of stable equilibrium with a change in the environment.

Changes in interaction with the environment lead to the evolution of the system. Such transformations are normal if the system maintains stable relations with the environment, and the process itself proceeds in accordance with the norms of its transformation. In case of loss of stability, the system is transformed or destroyed. At the same time, its orderliness disappears in this environment. This is also the norm of this kind of relationship.

In this paper, the norm is understood not as a fixed criterion, but as a process that determines the optimal mode of functioning of the system, i. e. its functional optimum. In this concept, the norm is interpreted as the interval of optimal functioning of a system with moving boundaries. Within these boundaries, the optimal relationship with the environment and the consistent performance of all functions of the system.

The authors consider the system as a unity "object-environment". There is the question of searching of statistical regularities that ensure the stability of the continuous process of adaptation of the system in this context, when the environment is change. The optimum of such process is normal process. And its most stable state (the analogy of the mode in the Gauss law of the probability density distribution of a random variable) is a reflection of the norm. In this case, the norm characterizes both the qualitative and potential capabilities of the system. The direction of the movement of the norm determines the qualitative evolution of the "object-environment" system.

The norm is characterized as the greatest reserve of stability of the system. This is due to the maximum range of deviations that ensure the return of the system to its original position. As the deviation from the norm, the system goes into a state of tension. At the same time, the variety of compensatory possibilities of the system decreases, and the time of conservation of this state is reduced. The reason of this effect: an increase in the intensity of the state requires an adequate increase in energy to relieve tension and transition to normal. The tension condition in which all power supplies goes to relieve tension, can be taken abroad the functional optimum. After that irreversible destabilizing processes are observed, which increase depending on the distance from the modal state of the system (norm). This regularity is shown in Fig. 2. The density of the distribution of the parameter of the final result is described by the Gaussian law. Within each state ("0", "1", "2"), the permissible deviations that stabilize its conservation can't go beyond the inflection 
points of the curve (respectively $\mu_{0} \pm \sigma_{0}, \mu_{1} \pm \sigma_{1}, \mu_{2} \pm \sigma_{2}$ ). If these deviations extend beyond the inflection points, the system goes into a new state with other characteristics of its conservation.

The same arguments can be repeated for the opposite direction of the direct states in Fig. 2 - half-line "relaxation". Therefore, all the constructions in the direction of "relaxation" will be symmetrical and not shown in Fig. 2.

The envelope of the permissible deviations of the parameter ensuring the stability of the state also corresponds to the Gaussian distribution curve (the lower part of Fig. 2). This allows to define the norm as a mathematical expectation in the envelope curve (at the point in Fig. 2), and the boundaries between its inflection points (the point and the "relaxation" symmetrical to it on the half-line) as a zone of the functional optimum. It is natural to assume that the greater the intensity of the state, the less sensitivity to small perturbations.

The norm is subject to the influence of the environment and therefore varies throughout the life cycle.

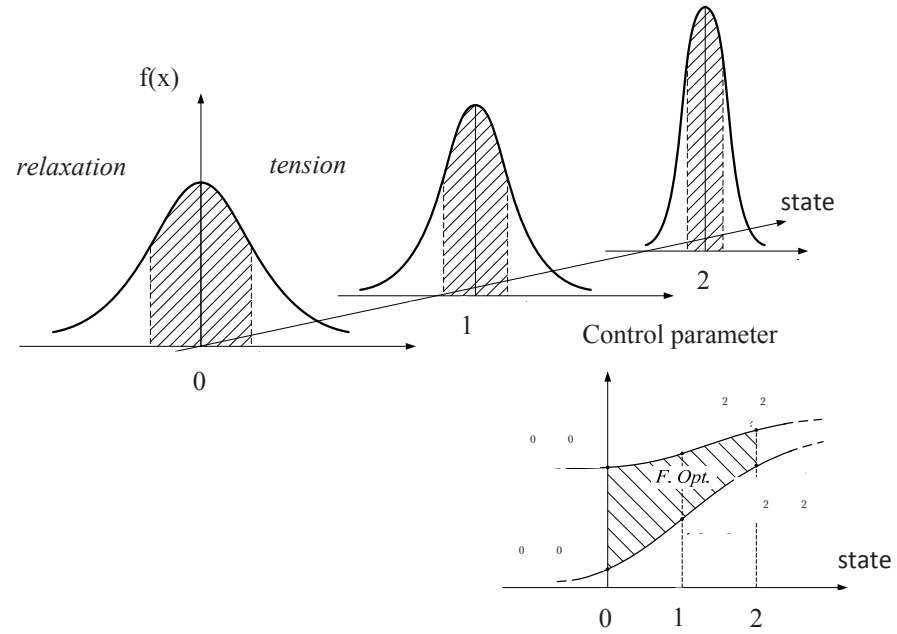

Fig. 2. Distribution of deviations of the control parameter relative to various values of activity intensity

If analyze the location of the norm, the variance and the rate of change, then it is possible to predict the state of the system and determine its adaptive capabilities. Dependence of the dispersion on the functional state allows to consider it as a criterion for estimating the individual norm of the system and the degree of tension.

\section{- «state $\in$ FOpt» block}

This block performs a comparison of state and FOpt in accordance with (1):

- if the state corresponds to norm (parameter state is inside the surface Fopt), then nothing needs to be changed in the behavior of the control object. This is indicated by the exit "yes" of the block;

- if the state does not correspond to the norm of the behavior of the control object, then it is necessary to make changes to the operation of the system (the output "no" of the block).

\section{- «It is necessary to correct the process» block}

There are three stages of adjustment:

Stage 1: Identifying of "bottlenecks" in the dynamics of the control parameter.

The principle of "bottleneck" is one of the basis of self-organization principles of MSOP [7]. At this stage, there is a complex analysis of the dynamics of the control parameter behavior according to the eight characteristics of systematization (see the block "Identification and systematization of parameters"): WHAT, WHERE, WHEN, WHY, HOW, WHO, TO WHOM, FOR WHAT. 
There are two manifestations of the bottleneck: "negative trend" and "maximum ejection". There may be several bottlenecks.

Stage 2: Analysis of cause-effect relationships.

At this stage, the most significant underlying causes are identified by analyzing the possible causes of the negative development of the process or the management object. They received the name of the premise. Their physical meaning is the cause of the causes.

One or more prerequisites are singled out.

Stage 3: Reducing the influence of "bottleneck".

This is a decision on options to reduce the influence of bottlenecks on the operation of a managed object and the implementation of these decisions.

The concrete content of this block depends to a large extent on each control object.

\section{Experimental procedures}

Formulation of the problem: The metallurgical enterprise "Interpipe" supplies products for the railway company. In accordance with the procedure at the enterprise, the quality of each melting is controlled by measuring the values of the control parameters. Total parameters are 14: $\mathrm{p}_{1}$, $\mathrm{p}_{2}, \ldots, \mathrm{p}_{14}$. Denote the vector of the control parameters as

$$
\overline{\mathrm{PAR}}=\left\|\mathrm{p}_{1}, \mathrm{p}_{2} \ldots, \mathrm{p}_{14}\right\|,
$$

The list of control parameters is presented in Table 1.

Table 1

Physical values of control parameters

\begin{tabular}{|c|c|c|c|c|c|c|c|c|c|c|c|c|c|c|}
\hline$i$ & 1 & 2 & 3 & 4 & 5 & 6 & 7 & 8 & 9 & 10 & 11 & 12 & 13 & 14 \\
\hline \multirow{2}{*}{ Physical values } & $\mathrm{C}$ & $\mathrm{Mg}$ & $\mathrm{Si}$ & $\mathrm{P}$ & $\mathrm{S}$ & $\mathrm{Cr}$ & $\mathrm{Ni}$ & $\mathrm{Cu}$ & $\begin{array}{c}\text { resid- } \\
\text { ual } \\
\text { action }\end{array}$ & $\begin{array}{c}\text { resis- } \\
\text { tance }\end{array}$ & $\begin{array}{c}\text { elonga- } \\
\text { tion }\end{array}$ & $\begin{array}{c}\text { con- } \\
\text { traction }\end{array}$ & $\begin{array}{c}\text { resilience } \\
\text { Chemical composition } \\
\text { ness }\end{array}$ \\
\cline { 2 - 9 } & \multicolumn{10}{c|}{ Mechanical properties } \\
\hline
\end{tabular}

Limits are denoted by the vector

$$
\overline{\mathrm{LIM}}=\left\|1_{1}, 1_{2}, \ldots, 1_{14}\right\| .
$$

Rules for the formation of $\mathrm{i}^{\text {th }}$ limit:

$$
1_{i}=\left\{\begin{array}{l}
\in\left[l_{i}^{\min }, l_{i}^{\max }\right], \text { or } \\
\geq 1_{i}^{\prime}, \text { or } \\
\leq 1_{i}^{\prime \prime}
\end{array}\right\}, i=\overline{1,14}
$$

The formula for the correspondence of the limit

$$
\mathrm{p}_{\mathrm{i}} \equiv 1_{\mathrm{i}}
$$

The object of control is melting. The annual volume of fusions is presented in the form of a set, which consists of melting's over 12 months:

$$
\overline{\mathrm{PLAV}}=\left\{\overline{\mathrm{PLAV}^{(1)}}, \overline{\mathrm{PLAV}^{(2)}}, \ldots, \overline{\mathrm{PLAV}^{(12)}}\right\},
$$

where $\overline{\operatorname{PLAV}^{(1)}}=\left\{\mathrm{pl}_{1}^{(1)}, \mathrm{pl}_{2}^{(1)}, \ldots, \mathrm{pl}_{\mathrm{I}_{1}}^{(1)}\right\}-$ melts in January ; 
$\overline{\mathrm{PLAV}^{(2)}}=\left\{\mathrm{pl}_{\mathrm{I}_{1}+1}^{(2)}, \mathrm{pl}_{\mathrm{I}_{1}+2}^{(2)}, \ldots, \mathrm{pl}_{\mathrm{I}_{2}}^{(2)}\right\}-$ melts in February;

$\overline{\mathrm{PLAV}^{(12)}}=\left\{\mathrm{pl}_{\mathrm{I}_{11}+1}^{(12)}, \mathrm{pl}_{\mathrm{I}_{11}+2}^{(12)}, \ldots, \mathrm{pl}_{\mathrm{I}_{12}}^{(12)}\right\}-$ melts in December.

Quality control is carried out in 2 stages:

Stage 1: values of the control parameters $\mathrm{p}_{1}, \mathrm{p}_{2}, \ldots, \mathrm{p}_{14}$ are compared with the limits according to the formula (5).

Step 2: the monthly statistics of the control parameters are processed by calculating the swings and assessing compliance with the Gaussian law in accordance with the "Shewhart control charts" $[15,16]$.

The solution of the problem.

From the authors' point of view, there are two shortcomings to the current quality control procedure:

- Lack of assessment of the state of the enterprise (normal, tense, border, etc.);

- Lack of assessment of the trend in the dynamics of the company's activities.

To address these shortcomings, let's apply the above-described theoretical approach. Below is the procedure for managing the product acceptance process:

Month number $\mathrm{j}=1$;

Melt number $\mathrm{k}=1$;

The formation of $\overline{\mathrm{PLAV}^{(\mathrm{j})}}$ a new value $\mathrm{p}_{\mathrm{i}}\left(\mathrm{pl}_{\mathrm{k}}^{(\mathrm{j})}\right)$ in accordance with $\underline{(6) \text {; }}$

checking $p_{i}$ for compliance with limits $l_{i}$ in accordance with (5), $i=\overline{1,14}$;

assessment of the compliance of statistics $p_{i}$ in the month $\mathrm{j}$ under the law of Gauss, $i=\overline{1,14}$;

the calculation of the moving boundaries $\mathrm{MR}\left(\mathrm{p}_{\mathrm{i}}\right)$ and $\overline{\mathrm{MR}\left(\mathrm{p}_{\mathrm{i}}\right)}, \mathrm{i}=\overline{1,14}$;

Formation of the current value FOpt:

if $0\left\langle\mathrm{MR}\left(\mathrm{p}_{\mathrm{i}}\right)\left\langle\overline{\mathrm{MR}\left(\mathrm{p}_{\mathrm{i}}\right)}\right.\right.$, then State $=$ '0';

if $\overline{\mathrm{MR}\left(\mathrm{p}_{\mathrm{i}}\right)} \leq \mathrm{MR}\left(\mathrm{p}_{\mathrm{i}}\right)<\overline{\mathrm{MR}\left(\mathrm{p}_{\mathrm{i}}\right)}+\sigma_{\mathrm{MT}\left(\mathrm{p}_{\mathrm{i}}\right)}$, then State $=' 1$ ';

if $\operatorname{MR}\left(\mathrm{p}_{\mathrm{i}}\right) \geq \overline{\mathrm{MR}\left(\mathrm{p}_{\mathrm{i}}\right)}+\sigma_{\mathrm{MT}\left(\mathrm{p}_{\mathrm{i}}\right.}$, then State='2'.

if State $=$ '0', then new values are defined $\mu_{0}$ and $\sigma_{0}$;

if State $=1$ ', then new values are defined $\mu_{1}$ and $\sigma_{1}$;

if State $=$ '2', then new values are defined $\mu_{2}$ and $\sigma_{2}$.

if $\mathrm{p}_{\mathrm{i}}\left(\mathrm{pl}_{\mathrm{k}}^{(\mathrm{j})}\right)$ does not correspond to FOpt, then $\mathrm{p}_{\mathrm{i}}\left(\mathrm{pl}_{\mathrm{k}}^{(\mathrm{j})}\right)$ is checked by four Shewhart criteria (numbers 1, 5, 6, 8).

transition to the input of information on $(\mathrm{k}+1)$-th melt.

calculation of possible indicators in accordance with the index reproducibility and suitability; transition to $(j+1)$-th month.

where ' 0 ', ' 1 ', ' 2 ' are the states of the enterprise that correspond to the notations Sost $_{0}$, Sost $_{1}$, Sost $_{2}$ on Fig. 2;

set " 0 ", set " 1 ", set " 2 " are a set of parameters $\mathrm{p}_{\mathrm{i}}\left(\mathrm{pl}_{\mathrm{k}}^{(\mathrm{j})}\right)$ that belong to the states ' 0 ', ' 1 ', '2' (or Sost $_{0}$, Sost $_{1}$, Sost $_{2}$ ) accordingly;

$\mu_{0}, \mu_{1}, \mu_{2}$ - mathematical expectation (average-arithmetic) of sets ' 0 ', ' 1 ', ' 2 ' accordingly;

$\sigma_{0}, \sigma_{1}, \sigma_{2}-$ standard deviation of sets ' 0 ', ' 1 ', '2' accordingly;

FOpt - the norm of behavior as functional optimum;

$\operatorname{MR}\left(\mathrm{p}_{\mathrm{i}}\right)$ - moving boundaries of $\mathrm{p}_{\mathrm{i}}$;

$\overline{\operatorname{MR}\left(\mathrm{p}_{\mathrm{i}}\right)}$ - average-arithmetic of moving boundaries $\operatorname{MR}\left(\mathrm{p}_{\mathrm{i}}\right)$;

$\sigma_{\mathrm{MR}\left(\mathrm{p}_{\mathrm{i}}\right)}-$ standard deviation of $\mathrm{MR}\left(\mathrm{p}_{\mathrm{i}}\right)$.

\section{Results and discussion}

1. The key concepts of the statistical regularity method are described - the theoretical basis for effective management of human functional activity and/or human-technical community $[17,18]$. This method is based on the principles of self-organization. The use of a functional optimum as a norm of behavior provides for a constant specification of the norm and its adaptation to 
changes in the interaction of the control object and the environment $[19,20]$. This is the nature of self-learning.

2. An example of the practical use of the method of statistical regularity for the real sector of the economy is given. This is the management of the quality of the technological process. The control parameter here is the final result of the activity of the metallurgical enterprise.

3. To implement any innovation, you need to represent the control information in a user-friendly form. Therefore, quality control of the technological process is presented in the form of an analysis of the chemical composition and mechanical properties of metallurgical melting.

\section{Conclusions}

1. A systematic approach is the method of statistical regularity. It allows to effectively manage not only by the technological process in metallurgical production (this is shown in the article), but also by a variety of other processes in industry, transport, and society.

2. The article shows how it is possible to select a small number of control parameters to manage by a complex technological process.

3. The development of scientific and technological progress made it possible to take into account the individual characteristics of the object of management. This is possible by using the optimum functional as a standard state activities.

\section{References}

[1] Leontiev, A. N. (1975). Activity. Consciousness. Personality. Moscow: Politizdat. Available at: https://www.marxists.org/russkij/leontiev/1975/dyeatyelnost/deyatyelnost-soznyanie-lichnost.pdf

[2] Talysina, N. F. (2003). The activity approach has not yet been implemented. It is necessary to build the psychology of actions. Journal of Practical Psychology, 1-2, 3-15.

[3] Samsonkin, V. N. (2016). System approach in organization management (application training). Certificate on filing of copyright of literary written work of scientific character, 64896.

[4] Bedny, G. Z. (2017). Application of Systemic-Structural Activity Theory to Design and Training. NY: CRC Press, 416.

[5] Leontiev, A. A. (2016). The life and creative path of A. N. Leontiev. Available at: http:// www.psy.msu.ru/people/leontiev/

[6] Samsonkin, V. N. (1997). Theoretical bases of the automated control of the human factor in human machine systems on the railway transport. Kharkiv: Kharkiv State University of Railway Transport, 440 .

[7] Samsonkin, V. N., Druz, V. A. (2005). The method of statistical regularity in the management of traffic safety in railway transport. Donetsk: DIRT, 160.

[8] Puhach, Ya. I. (2012). Modeling of creative activity as a projection of intellectual activity in intellectual computer systems (morpho-functional organization of thinking activity). Slobozhansky science and sports journal, 4, 152-158.

[9] Puhach, Ya. I. (2013). Basic provisions for constructing a semantic space for the orderly presentation of research results. Materials of the IX International Scientific and Practical Conference «Future Issues of Peace and Science». Vol. 39. Sofia: «Bial Grad - BG», 5-13.

[10] Romanovskii, A. G., Druz, V. A., Yurieva, I. A. (2008). Socio-psychological foundations of building the process of managing communicative relations. Kharkiv: NTU «KhPI», 239.

[11] Balabanova, L. M., Druz, V. A., Zhurov, M. S. et al. (2004). Man in the dimensions of the twentieth century. The progress of mankind in the twentieth century. Vol. 5. Moscow: Publishing House of the International Academy of Human Problems in Aviation and Astronautics, 84-96. 
[12] Samsonkin, V. N., Druz, V. A., Fedorovich, E. S. (2010). Modeling in self-organizing systems. Donetsk: Zaslavskiy, 104.

[13] Anokhin, P. K. (1975). Essays on the Physiology of Functional Systems. Moscow: Medicine, 448.

[14] Anokhin, P. K. (1980). Nodal questions of the functional system. Moscow: Science, 197.

[15] ISO 7870-2:2013. Preview Control charts - Part 2: Shewhart control charts. Available at: https://www.iso.org/standard/40174.html

[16] Samsonkin, V. N., Diomin, R. Yu., Viddi, V. et al. (2015). Technique of definition of norm as zones of the functional optimum of production at quality control of production. Certificate on filing of copyright of literary written work of scientific character, 61849.

[17] Larue, G. S., Rakotonirainy, A., Haworth, N. L., Darvell, M. (2015). Assessing driver acceptance of Intelligent Transport Systems in the context of railway level crossings. Transportation Research Part F: Traffic Psychology and Behaviour, 30, 1-13. doi: 10.1016/j.trf.2015.02.003

[18] Samsonkin, V. N. (2016). Rationale and key principles of corporate university PJSC «Ukrainian Railways» to prepare TOP reserve management. Certificate on filing of copyright of literary written work of scientific character, 64868.

[19] Hojjati-Emami, K., Dhillon, B. S., Jenab, K. (2013). The Integrative Time-Dependent Modeling of the Reliability and Failure of the Causes of Drivers' Error Leading to Road Accidents. International Journal of Strategic Decision Sciences, 4 (1), 25-39. doi: 10.4018/jsds.2013010102

[20] Samsonkin, V., Petinov, Y. (2016). Development of the method of efficient monitoring of the main activity of a train driver. Eastern-European Journal of Enterprise Technologies, 3 (3 (81)), 52-58. doi: 10.15587/1729-4061.2016.71703 